\title{
Impact of Maternal Over-nutrition during Pregnancy on Maternal Oxidative Stress and Fetal Skeletal/Visceral Anomalies of the Rats
}

\author{
Débora Cristina Damasceno"*, Bruna Dallaqua1, Isabela Lovizutto lessi', Gustavo Tadeu Volpato ${ }^{1,2}$ and Kleber Eduardo Campos ${ }^{1,2}$
}

${ }^{1}$ Laboratory of Experimental Research in Gynecology and Obstetrics, Botucatu Medical School, Univ Estadual Paulista_UNESP, São Paulo State, Brazil ${ }^{2}$ Institute of Biological and Health Sciences, University Center of Araguaia, University of Mato Grosso (UFMT), Mato Grosso State, Brazil

\begin{abstract}
The maternal food supply, nutrition and metabolism leads to lifelong consequences for the health of the infants. Experimental models have been developed to explore these repercussions. We intended (1) to verify the influence of a maternal overnutrition on the maternal oxidative stress in pregnant rat, (2) to evaluate if the maternal oxidative stress interferes on the fetal growth, and (3) to analyze external, skeletal and visceral fetal anomalies. On day 0 of pregnancy, the rats were randomly distributed into two groups ( $n=21$ rats/group): Control group - fed regular diet; Overnutrition group - fed high caloric diet, which was made by mixing the supplemented ingredients to a previously triturated Purina Chow. On day 21 of pregnancy, the rats were euthanized to evaluate reproductive outcomes and fetal development, and to obtain blood samples for maternal metabolic parameters. The fetal weights were significantly reduced after overnutrition treatment during pregnancy. The overnoutrished rats presented higher malonaldehyde-MDA and thiol group concentrations and superoxide dismutase (SOD) activity whereas glutathione peroxidase (GSH-Px) activity was lower. The fetuses from overnutrition group presented higher frequency of skeletal and visceral anomalies. Thus, the overnutrition caused metabolic changes in the maternal organism, particularly in oxidative metabolism, which impaired the fetal growth and development, showing harmful effect of a hypercaloric diet during pregnancy.
\end{abstract}

Keywords: Anomaly; Overnutrition; Obesity; Oxidative stress; Pregnancy; Rat

\section{Introduction}

The World Health Organization (WHO) characterizes obesity as an epidemic problem, with a higher prevalence in females in reproductive age. The reason behind this epidemic is not clear. In the gestational period, the obesity is considered a high-risk state because it is associated with much comorbidity $[1,2]$. Therefore, food supply and metabolism in the women during pregnancy and lactation and in their children have marked implications on child development and long-term health.

During pregnancy, the availability of nutrients to the fetus depends on placental supply and maternal nutrition. There are evidences that alterations in fetal nutrition and endocrine status lead in developmental adaptations, which perpetually change structure, physiology, and metabolism. This fact predisposes individuals to disease in adult life - "fetal origins adult diseases (FOAD)" [3]. There was advance in this field and according other researchers Barker's theory was adapted to developmental origins of health and disease $(\mathrm{DOHaD})$. There are two important reasons for the change. The first is because the development process, which may constitute a risk for late onset of diseases, occurs not only during the fetal period, but also throughout the development period of plasticity. Another reason is that DOHaD terminology has implications not only for disease and its prevention, but also for health advancement [4].

In animal models, the high-fat diet (cafeteria) was effective in inducing obesity, as demonstrated by Akyol et al. [5] without affecting reproductive success or circulating lipid concentrations. This study successfully demonstrated that there were differential effects of maternal body fatness and diet on the fetal and placental growth, with pre-gestational obesity leading to lower fetal weight on day 20 of pregnancy.

We hypothesized that overnutrition causes maternal metabolic changes related to abnormal lipid profile and oxidative stress, leading to an inadequate intrauterine environment, which impairs fetal development. Then, the objectives in the present study were a) to verify the influence of overnutrition in pregnant rat on the maternal oxidative stress, b) to evaluate if the maternal oxidative stress interferes on the fetal growth, and c) to analyze fetal development in the presence of the altered intrauterine environment due to an overnutrition.

\section{Materials and Method}

\section{Animals}

Female and male Wistar rats weighing approximately $190 \mathrm{~g}$ and 220 g, respectively, were obtained from CEMIB (Multidisciplinary Center for Biological Research) - Campinas State University (UNICAMP). These animals were adapted in vivarium of Laboratory of System Physiology and Reproductive Toxicology (FISIOTOX), and were maintained under standard laboratory conditions $\left(22 \pm 3^{\circ} \mathrm{C}, 12 \mathrm{~h} \mathrm{light} /\right.$ dark cycle), with pelleted food and tap water ad libitum. The animals were cared for in accordance with the principles of the Guide for Care and Use of Experimental Animals. The local Committee of Ethics in Animal Experimentation approved all experimental procedures of this study.

${ }^{*}$ Corresponding author: Débora Cristina Damasceno, Laboratory of Experimental Research in Gynecology and Obstetrics, Botucatu Medical School, Univ Estadual Paulista_UNESP, São Paulo State, Brazil, Tel: +55 14 38801631; E-mail damascenofmb@gmail.com

Received February 04, 2016; Accepted March 02, 2016; Published March 09, 2016

Citation: Damasceno DC, Dallaqua B, lessi IL, Volpato GT, Campos KE (2016) Impact of Maternal Over-nutrition during Pregnancy on Maternal Oxidative Stress and Fetal Skeletal/Visceral Anomalies of the Rats. J Nutr Disorders Ther 6: 185 doi:10.4172/2161- 0509.1000185

Copyright: () 2016 Damasceno DC, et al. This is an open-access article distributed under the terms of the Creative Commons Attribution License, which permits unrestricted use, distribution, and reproduction in any medium, provided the original author and source are credited. 


\section{Experimental design}

After two weeks of acclimatization, adult virgin female Wistar rats were mated overnight with male Wistar rats. The morning on which sperm were found in the vaginal smear was designated Gestational Day 0 [6]. The female rats were randomly distributed into two groups ( $\mathrm{n}=21$ rats/group): Control group - fed regular diet; Overnutrition group - fed high caloric diet from day 0 to day 21 of pregnancy (whole pregnancy). The Control group given Purina Rodent Chow (Purina $^{\circledR}$, São Paulo State, Brazil) $(26.5 \%$ protein, $3.8 \%$ fat, $40.0 \%$ carbohydrate, $4.5 \%$ crude fiber and $3.0 \mathrm{Kcal}$ g-1 metabolizable energy). The Overnutrition group was fed hypercaloric diet presenting $4.4 \mathrm{Kcal}$ $\mathrm{g}^{-1}$. Hypercaloric diet was performed adding in $37 \%$ of Purina Rodent Chow, $25 \%$ toasted peanut, 33\% milk chocolate and 5\% liquid butter. In bromatological tests the hyercaloric diet contained $20.5 \%$ of protein, $47 \%$ carbohydrate, $28.5 \%$ fat and $4 \%$ fibre. Diets were administered as pellets and food consumption was weekly measured (9:00 - 10:00 a.m.). Therefore, all diets provided sufficient amounts of vitamins, minerals, essential amino acids and lipids

\section{Evaluation at term of pregnancy (reproductive performance)}

On day 21 of pregnancy, the rats were anaesthetized with sodium pentobarbital (Hypnol $\left.{ }^{\mathbb{B}} 3 \%\right)$. The uterus was removed and weighed, and the ovaries and uterine contents examined to determine the number of corpora lutea, implantation sites, and resorptions (embryonic death), number of alive or dead fetuses. The rate of embryonic loss before implantation was calculated as: number of corpora lutea - number of implantation $\times 100 /$ number of corpora lutea and used as a measure of failed conceptional effect or preimplantation loss. The percentage embryonic loss after implantation was calculated as: number of implantation - number of live fetuses $\times 100 /$ number of implantation and used as a measure of abortifacient effect [7]. In the lack of visible implantation sites the uterine corns were stained with a preparation of $10 \%$ ammonium sulphate [8].

Immediately after exploratory laparotomy, all alive fetuses were weighed. Following, the female newborns were separated and classified by the mean $\pm 1.0 \times$ standard deviation (SD) according to the mean values of fetal weights of the control group as: small for pregnancy age (SPA) when weight was smaller than mean of the control group $-1.0 \times$ $\mathrm{SD}$; appropriate for pregnancy age when weight was into of the mean values of control group (mean $\pm 1.0 \times \mathrm{SD}$ ); and large for pregnancy age (LPA) when weight was superior to mean of control group $+1.0 \times \mathrm{SD}$ [9]. The data were presented as percentual values.

\section{Maternal oxidative stress status}

Blood samples were put into anticoagulant tubes (heparin), centrifuged at $90 \mathrm{xg}$ for $10 \mathrm{~min}$ at room temperature for assay of oxidative stress biomarkers, which were estimated in the washed erythrocytes. The malonaldehyde (MDA) and thiol groups concentrations were used as biomarkers of lipid peroxidation while superoxide dismutase (SOD) and glutathione peroxidase (GSH-Px) activities as parameters of antioxidant capacity. SOD enzymatic activity unit was defined as SOD units able to produce $50 \%$ of pyrogallol oxidation inhibition. All data were expressed in units of SOD per milligram of hemoglobin. Thiol groups were enzymatically determined using 5,5'- dithiobis (2-nitrobenzoic acid) (DTNB) and glutathione reductase in the presence of a reduced form of nicotinamide adenine dinucleotide phosphate (NADPH), forming 2-nitro-5-thiobenzoic acid. Thiol group determination was measured at $412 \mathrm{~nm}$ on a spectrophotometer. One unit of its activity was equal to the micromolar of substrate reduced per gram of hemoglobin. GSH-Px content was performed by monitoring
NADPH oxidation. GSH-Px activity was expressed in enzymatic activity units per gram of hemoglobin (IU/gHb). For MDA concentration, the absorbance was measured at a wavelength of $535 \mathrm{~nm}$, and the results were expressed as $\mathrm{nM}$ of MDA per gram of hemoglobin $(\mathrm{nM} / \mathrm{g} \mathrm{Hb})$ according protocol of our laboratory [6].

\section{Analysis of external, skeletal and visceral fetal anomalies}

The fetuses were weighed and analyzed for the presence of external anomalies. After this analysis, half of the fetuses were fixed in Bodian's solution and serial sections prepared as described by Wilson [10] for visceral examination. The remaining fetuses were prepared for skeletal examination by the staining procedure of Staples and Schnell [11]. Besides the skeletal analyses, the counting of the ossification sites was performed according to methodology proposed by Aliverti et al. [12] for determining the degree of fetal development.

\section{Statistical analysis}

For comparison between groups, a one-way layout was applied for the groups with $\mathrm{F}$ test for mean values. Chi-square test was used for percentage, with zero-inflated Poisson test was applied in skeletal fetal anomalies, and negative binomial distribution was used for visceral fetal anomalies. Statistical significance was considered as $\mathrm{p}<0.05$.

\section{Results}

\section{Maternal data}

The maternal reproductive outcomes of rats fed hypercaloric diet during pregnancy presented no changes compared to control rats (Table 1).

It was verified higher erythrocyte SOD activity, thiol group and MDA concentrations, and lower GSH-Px activity in hypercaloric-dietfed female rats compared with those of control rats (Table 2).

\section{Fetal outcomes}

The birth weight of offspring was significantly reduced after hypercaloric diet treatment during pregnancy. It was observed increased rate of newborns classified as small for pregnancy age and reduced percentage of fetuses as appropriate and large for pregnancy age compared to those of control rats (Table 3). The fetuses of the hypercaloric-diet-fed rats did not show any external abnormality compared to fetuses from control groups. The frequency of skeletal anomalies (craniofenestria, incomplete ossification of sternebra and abnormally shaped of sternebra) was higher in the fetuses of overnoutrished rats during pregnancy compared to those of control (Figure 1). In relation to visceral anomalies, the fetuses of hypercaloricdiet-fed rats presented higher incidence of hydroureter compared to fetuses from control rats (Table 4).

\section{Discussion}

In the present study, it was demonstrated the overnutrition group presented an increased total food intake (data not shown), as described previously in the literature with animals fed hypercaloric diets because of higher palatability of its ingredients [5]. The increasing in energy intake may explain a tendency to higher body weight in the overnutrition group. Taylor et al. [13] verified female rats fed for 10 days prior to pregnancy and throughout gestation with $20 \% \mathrm{w} / \mathrm{w}$ lard, vitamins, essential micronutrients and proteins present no difference on final body weight at term pregnancy. Keesey and Hirvonen [14] suggest that the lack of weight gain could be explained by hypothalamic mechanisms, which establishes a set point that body weight and fat 
Citation: Damasceno DC, Dallaqua B, lessi IL, Volpato GT, Campos KE (2016) Impact of Maternal Over-nutrition during Pregnancy on Maternal Oxidative Stress and Fetal Skeletal/Visceral Anomalies of the Rats. J Nutr Disorders Ther 6: 185. doi:10.4172/2161- 0509.1000185

Page 3 of 5

\begin{tabular}{|c|c|c|}
\hline \multirow[t]{2}{*}{ Variables } & \multicolumn{2}{|c|}{ Groups } \\
\hline & $\begin{array}{l}\text { Control } \\
(n=21)\end{array}$ & $\begin{array}{l}\text { Overnutrition } \\
(n=21)\end{array}$ \\
\hline $\begin{array}{c}\text { Corpora lutea } \\
\text { Total }(\mathrm{N}) \\
\text { Mean } \pm \mathrm{SD}\end{array}$ & $\begin{array}{c}280 \\
13.33 \pm 1.62\end{array}$ & $\begin{array}{c}293 \\
13.31 \pm 2.41\end{array}$ \\
\hline $\begin{array}{l}\text { Implantation } \\
\text { Total }(\mathrm{N}) \\
\text { Mean } \pm \mathrm{SD}\end{array}$ & $\begin{array}{c}260 \\
12.38 \pm 2.10\end{array}$ & $\begin{array}{c}268 \\
12.18 \pm 2.32\end{array}$ \\
\hline $\begin{array}{l}\text { Alive fetuses } \\
\text { Total (N) } \\
\text { Mean } \pm \text { SD } \\
\text { Per implantation sites (\%) }\end{array}$ & $\begin{array}{c}243 \\
11.57 \pm 2.90 \\
93.46\end{array}$ & $\begin{array}{l}254 \\
11.54 \pm 2.57 \\
94.78\end{array}$ \\
\hline $\begin{array}{l}\text { Dead fetuses } \\
\text { Total }(\mathrm{N}) \\
\text { Mean } \pm \mathrm{SD}\end{array}$ & $\begin{array}{c}0 \\
0.00 \pm 0.00\end{array}$ & $\begin{array}{c}0 \\
0.00 \pm 0.00\end{array}$ \\
\hline $\begin{array}{l}\text { Resorptions (Embryonic death) } \\
\text { Total (N) } \\
\text { Mean } \pm \text { SD } \\
\text { Per implantation sites (\%) }\end{array}$ & $\begin{array}{c}17 \\
0.81 \pm 1.29 \\
6.54\end{array}$ & $\begin{array}{c}13 \\
0.59 \pm 0.91 \\
4.85\end{array}$ \\
\hline Maternal weight gain $(\mathrm{g})$ & $121.00 \pm 27.23$ & $123.23 \pm 20.61$ \\
\hline Gravid uterus weight (g) & $80.46 \pm 19.57$ & $73.23 \pm 14.91$ \\
\hline $\begin{array}{l}\text { Maternal weight gain minus gravid } \\
\text { uterus weight }(\mathrm{g})\end{array}$ & $40.54 \pm 14.48$ & $49.99 \pm 18.44$ \\
\hline
\end{tabular}

Legend: $\mathrm{N}=$ number

Data shown as mean \pm standard deviation (SD) and proportions (\%).

$p>0.05$ - non significant difference

Table 1: Reproductive outcomes at term pregnancy from rats fed control and overnutrition diet.

\begin{tabular}{|c|c|c|}
\hline \multirow[t]{2}{*}{ Variables } & \multicolumn{2}{|c|}{ Groups } \\
\hline & Control & Overnutrition \\
\hline MDA $\left(\mathrm{nmol} \mathrm{g}{ }^{-1} \mathrm{Hb}\right)$ & $50.34 \pm 7.84$ & $571.43 \pm 154.03$ \\
\hline $\mathrm{SOD}\left(\mathrm{IU} \mathrm{mg} \mathrm{mb}^{-1} \mathrm{Hb}\right)$ & $1.99 \pm 0.43$ & $20.22 \pm 9.66^{*}$ \\
\hline GSH-Px $\left(\mathrm{IU} \mathrm{g}^{-1} \mathrm{Hb}\right)$ & $90.72 \pm 32.28$ & $0.71 \pm 0.57^{*}$ \\
\hline Thiol groups $\left(\mu \mathrm{mol} \mathrm{g}{ }^{-1} \mathrm{Hb}\right)$ & $1.06 \pm 0.42$ & $10.52 \pm 3.65^{*}$ \\
\hline
\end{tabular}

Legend: $\mathrm{MDA}=$ malonaldehyde; $\mathrm{SOD}=$ superoxide dismutase; $\mathrm{GSH}-\mathrm{Px}=$ glutathione peroxidase.

Data presented as mean \pm standard deviation

" $p<0.05$ - compared to control group (F Test)

Table 2: Oxidative stress status from rats fed control and overnutrition diet during pregnancy.

\begin{tabular}{|c|c|c|}
\hline Variables & \multicolumn{2}{|c|}{ Groups } \\
\hline & $\begin{array}{c}\text { Control } \\
(\mathrm{n}=243)\end{array}$ & $\begin{array}{c}\text { Overnutrition } \\
(\mathrm{n}=254)\end{array}$ \\
\hline $\begin{array}{c}\text { Fetal body weight }(\mathrm{g}) \\
\text { Mean } \pm \text { SD }\end{array}$ & $5.36 \pm 0.41$ & $4.92 \pm 0.38^{*}$ \\
\hline SPA Fetuses (\%) & 11.11 & $51.58^{\#}$ \\
\hline APA Fetuses (\%) & 75.31 & $47.24^{\#}$ \\
\hline LPA Fetuses (\%) & 13.58 & $1.18^{\#}$ \\
\hline
\end{tabular}

Legend: $N=$ number; $S P A=$ small for pregnancy age; $A P A=$ adequate for pregnancy age; LPA = large for pregnancy age

Data shown as mean \pm standard deviation (SD) and proportions (\%).

$\mathrm{p}<0.05$ - compared to control group ("F Test; "Chi square test)

Table 3: Fetal weight and size classification at term pregnancy from rats fed control and overnutrition diet.

mass are regulated through coordinated adjustment to both energy intake and expenditure. On the other hand, studies show female Wistar rats exposed to high-fat diet during pregnancy and lactation presented an increased maternal body weight at parturition and at the end of lactation, showing that the hypercaloric diet resulted in an increased

energy intake confirmed by an increased body fat and prevented body weight loss in lactating rats [15].

The present study also evaluated the effect of hypercaloric diet during pregnancy on the reproductive outcomes. It was observed that this type of diet did not interfere on the ovulation, embryonic implantation and number of live fetuses. Nevertheless, the offspring from rats received hypercaloric diet born small for pregnancy age, confirming an intrauterine growth restriction during pregnancy. This result corroborates Francia-Farje et al. [16] who induced the obesity in Wistar rats providing a hypercaloric diet for 15 weeks prior pregnancy and during whole pregnancy. There is evidence that obese women at the beginning of pregnancy also present increased fetal complications. These women and their babies are at high risk of pregnancy complications, and of programming for metabolic disease in adult life [17]. In particular, maternal obesity is associated with disturbed fetal growth [18].

It was verified in our study that the overnutrition group presented imbalance between the production of reactive oxygen species and the antioxidant defense system. Despite an increased activity of SOD, it was observed an increased lipoperoxidation, resulting to oxidative stress. This status contributes to metabolic abnormalities that are associated to intense nutrient oxidation [18], contributing to impaired embryofetal growth and development. The hypercaloric free intake associated or not with increased oxidative stress may be related to some anomalies. In this study, the fetuses from rats fed hypercaloric diet presented an increased number of incomplete ossifications and abnormally shaped of sternebra, craniofenestria and hydrourether. These changes may be also associated with the modifications of low birth fetal weight because of an oxidative stress-induced adverse intrauterine environment to the embryofetal development [19].
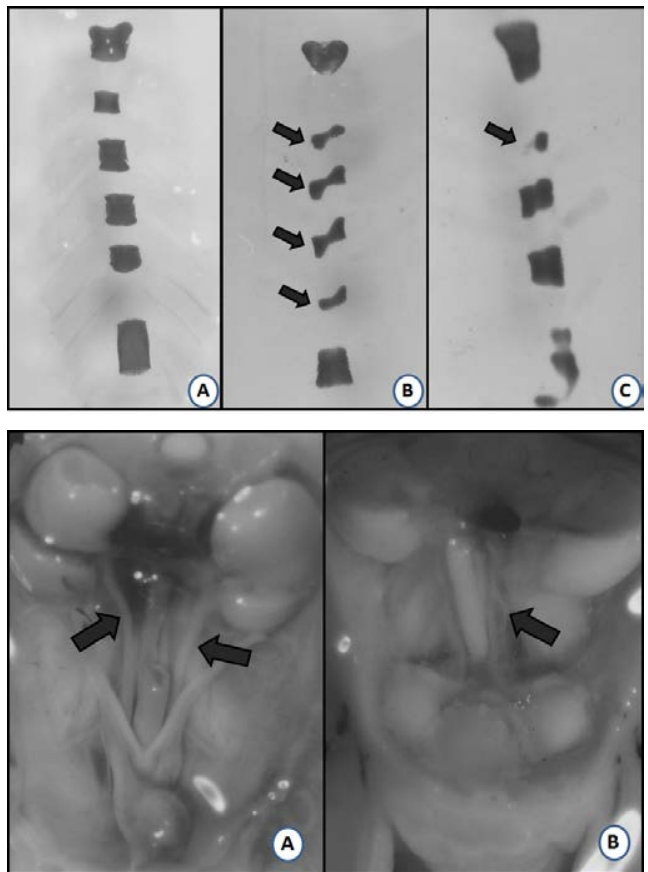

Figure 1: Photographs of rat fetuses. In superior photo: Normal fetus (A) and fetuses with skeletal fetal anomalies (B. Abnormally shaped sternebra, C. Incomplete ossification of sternebra). In inferior photo: Normal fetus (A) and fetuses with visceral fetal anomalies (B. Hydroureter). The anomalies are indicated by arrow. 
Citation: Damasceno DC, Dallaqua B, lessi IL, Volpato GT, Campos KE (2016) Impact of Maternal Over-nutrition during Pregnancy on Maternal Oxidative Stress and Fetal Skeletal/Visceral Anomalies of the Rats. J Nutr Disorders Ther 6: 185. doi:10.4172/2161- 0509.1000185

Page 4 of 5

\begin{tabular}{|c|c|c|}
\hline \multirow{2}{*}{ Variables } & \multicolumn{2}{|c|}{ Groups } \\
\hline & Control & Overnutrition \\
\hline \multicolumn{3}{|l|}{ External anomalies } \\
\hline Number fetuses examined (litter) & $243(21)$ & $254(22)$ \\
\hline Total number of fetuses (\%) with alteration & $1(0.4 \%)$ & $2(0.7 \%)$ \\
\hline Macroglossia & $1(0.4 \%)$ & $2(0.7 \%)$ \\
\hline \multicolumn{3}{|l|}{ Skeletal anomalies $^{a}$} \\
\hline Number fetuses examined (litter) & $120(21)$ & $134(22)$ \\
\hline Total number of fetuses (\%) with alteration & $55(45.8 \%)$ & $114(85.0 \%)^{*}$ \\
\hline Dumbbell ossification of vertebral centrum & $6(5.0 \%)$ & $6(4.4 \%)$ \\
\hline Bipartite ossification of vertebral centrum & $8(6.6 \%)$ & $1(0.7 \%)$ \\
\hline Incomplete ossification of vertebral centrum & $0(0.0 \%)$ & $1(0.7 \%)$ \\
\hline Supernumerary rib & $21(17.5 \%)$ & $22(16.4 \%)$ \\
\hline Fused rib & $1(0.8 \%)$ & $0(0.0 \%)$ \\
\hline Small rib & $1(0.8 \%)$ & $0(0.0 \%)$ \\
\hline Incomplete ossification of sternebra & $26(21.6 \%)$ & $126(94.0 \%)^{*}$ \\
\hline Abnormally shaped sternebra & $12(10.0 \%)$ & $41(30.6 \%)^{*}$ \\
\hline Angulated sternebra & $1(0.8 \%)$ & $1(0.7 \%)$ \\
\hline Sternebra agenesis & $2(1.6 \%)$ & $0(0.0 \%)$ \\
\hline Craniofenestria & $0(0.0 \%)$ & $22(16.4 \%)^{*}$ \\
\hline Palatine agenesis & $1(0.8 \%)$ & $0(0.0 \%)$ \\
\hline \multicolumn{3}{|l|}{ Visceral anomalies $^{b}$} \\
\hline Number fetuses examined (litter) & $111(21)$ & $120(22)$ \\
\hline Total number of fetuses (\%) with alteration & $31(27.9 \%)$ & $45(37.5 \%)$ \\
\hline Hydroureter & $20(18.0 \%)$ & $39(32.5 \%)^{*}$ \\
\hline Enlarged bladder & $1(0.9 \%)$ & $1(0.8 \%)$ \\
\hline Hydronephrosis & $1(0.9 \%)$ & $5(4.1 \%)$ \\
\hline Ectopic kidney & $8(7.2 \%)$ & $0(0.0 \%)$ \\
\hline Dilated esophagus & $1(0.9 \%)$ & $0(0.0 \%)$ \\
\hline
\end{tabular}

and metabolism of these offspring [16]. In conclusion, the results of this study suggest that, despite the hypercaloric diet given in rats only during pregnancy, confirms impaired fetal growth and development induced by oxidative stress-induced maternal complications, confirming a harmful effect of a hypercaloric diet during pregnancy and is a risk factor for maternal and fetal organisms.

\section{Acknowledgements}

The authors are grateful to Benedito Claudio da Silva, Natália Shwarz and Gisele Gomes for the technical assistance and to the Research Support Office (EAP) of the Botucatu Medical School, Univ Estadual Paulista_UNESP, for its valuable contribution in the study design and statistical analysis.

\section{References}

1. Satpathy HK, Fleming A, Frey D, Barsoom M, Satpathy C, et al. (2008) Maternal obesity and pregnancy. Postgrad Med 3: 1-9.

2. Willis K, Lieberman N, Sheiner E (2014) Pregnancy and neonatal outcome after bariatric surgery. Best Pract Res Clin Obstet Gynaecol 14: 156-164.

3. Barker DJP (1995) Fetal origins of coronary heart disease. BMJ 311: 171-174.

4. Gluckman PD, Hanson MA, Buklijas T (2010) A conceptual framework for the developmental origins of health and disease. J Dev Origins Health Disease 1: 6-18.

5. Akyol A, Langley-Evans SC, Mcmullen S (2009) Obesity induced by cafeteria feeding and pregnancy outcome in the rat. Br J Nutr 102: 1601-1610.

6. Damasceno DC, Sinzato YK, Lima PH, de Souza MS, Campos KE, et al (2011) Effects of exposure to cigarette smoke prior to pregnancy in diabetic rats. Diabetol Metab Syndr 3: 20-27

7. Damasceno DC, Kempinas Wilma DG, Volpato GT, Consonni M, et al. (2008) Anomalias Congênitas - Estudos Experimentais. Editora Coopmed. Belo Horizonte, Brasil.

8. Salewski E (1964) Farbemethode zum markroskopishen nachweis von implantatconsstellen an uterus der ratter naunyn schmuderbergs. Naunyn Schmiedebergs. Arch Exp Pathol Pharmakol 247: 121-135.

9. Volpato GT, Calderon IM, Sinzato S, Campos KE, Rudge MV, et al. (2011) Effect of Morus nigra aqueous extract treatment on the maternal-fetal outcome, oxidative stress status and lipid profile of streptozotocin-induced diabetic rats J Ethnopharmacol 118: 691-696.

10. Wilson JG (1965) Methods for administering agents and detecting malformations in experimental animals. Teratology - principles and techinique. University of Chicago Press, Chicago, United States.

11. Staples RE, Schnell $L$ (1964) Refinements in rapid clearing technique in the $\mathrm{KOH}$-alizarin red S method for fetal bone. Stain Technol 39: 61-63. to pregnancy complications and development of congenital anomalies [20,21]. Infants of obese mothers are at increased risk of birth difficulties and perinatal death $[22,23]$. However, the relation between maternal obesity and other birth defects is not as well defined and these findings have not been consistent among different studies [22]. During pregnancy, the urinary system is influenced by female sex hormones, and then fetal organism is more susceptible since that these individuals are in embryonic development. It was evidenced in this study the offspring from overnoutrished rats presented higher frequency of hydroureter. The literature shows that the fetal obstructive uropathy by hydroureter continues to represent a major cause of renal failure in children [24]. In addition, the experimental and human studies showed decreased numbers of nephron and correlated with low birth weight, which might be related as an indirect biomarker of fewer nephrons. Low birth weight in term newborns was shown to be associated with increased susceptibility to many subsequent diseases in adulthood [25].

Therefore, the rats submitted to overnutrition during pregnancy presented an adverse maternal intrauterine environment, confirmed by maternal oxidative stress. This alteration in the maternal organism impaired structural and functional adaptations during fetal development, confirmed by at birth low weight and fetal anomalies. These findings might contribute with late consequences for growth

12. Aliverti V, Bonanomi L, Giavini E (1979) The extent of fetal ossification as an index of delayed development in teratogenic studies on the rat. Teratology 20 : 237-242.

13. Taylor PD, Khan IY, Lakasing L, Dekou V, O'brien-Coker I, et al. (2003) Uterine artery function in pregnant rats fed a diet supplemented with animal lard. Exp Physiol 88: 389-398.

14. Keesey RE, Hirvonen MD (1997) Body weight set-points: determination and adjustment. Nutr 127: 1875S-1883S.

15. Bouanane S, Benkalfat NB, Baba Ahmed FZ, Merzouk $\mathrm{H}$, Mokhtari NS, et al. (2009) Time course of changes in serum oxidant/antioxidant status in overfed obese rats and their offspring. Clin Sci (Lond) 116: 669-680.

16. Francia-Farje LA, Silva DS, Volpato GT, Fernandes GS, Carnietto N, et al. (2010) Sibutramine effects on the reproductive performance of pregnant overweight and non-overweight rats. J Toxicol Environ Health A 73: 985-990.

17. Aerts L, Van Assche FA (2006) Animal evidence for the transgenerational development of diabetes mellitus. Int J Biochem Cell Biol 38: 894-903.

18. Higgins L, Greenwood SL, Wareing M, Sibley CP, Mills TA (2011) Obesity and the placenta: A consideration of nutrient exchange mechanisms in relation to aberrant fetal growth. Placenta 32: 1-7.

19. Khan NI, Naz L, Yasmeen G (2006) Obesity: an independent risk factor for systemic oxidative stress. Pak J Pharm Sci 19: 62-65. 
Citation: Damasceno DC, Dallaqua B, lessi IL, Volpato GT, Campos KE (2016) Impact of Maternal Over-nutrition during Pregnancy on Maternal Oxidative Stress and Fetal Skeletal/Visceral Anomalies of the Rats. J Nutr Disorders Ther 6: 185. doi:10.4172/2161- 0509.1000185

20. King JC (2006) Maternal obesity, metabolism and pregnancy outcomes. Annu Rev Nutr 26: 271-291.

21. Walsh SW (2007) Obesity: a risk factor for preeclampsia. Trends Endocrinol Metab 18: 365-370.

22. Whitaker RC (2004) Predicting preschooler obesity at birth: the role of maternal obesity in early pregnancy. Pediatrics 114: 29-36.

23. Lawlor DA, Smith GD, O'Callaghan M, Alati R, Mamun AA, et al. (2007)
Epidemiologic evidence for the fetal overnutrition hypothesis: findings from the mater-university study of pregnancy and its outcomes. Am J Epidemiol 165 418-424.

24. Temelcos C, Hutson JM (2004) Ontogeny of the VATER kidney in a rat model. The anatomical record. Part A. Discov Mol Cel Evoluc Biol 278: 520-527.

25. Plagemann A (2006) Perinatal nutrition and hormone-dependent programming of food intake. Horm Res 65: 83-89. 